\title{
Rammya Mathew: Professionalism in a time of crisis
}

\author{
Rammya Mathew GP \\ London
}

In recent years doctors have been accused of lacking professionalism, and many of us have suffered with self-doubt as a result. Now, however, our NHS workforce is witnessing a global pandemic on a scale we haven't experienced before. We've had to plan at length, reorganise structures, and redeploy our staff to ensure that we're as prepared as we can be for the coming weeks and months.

None of this has happened without effort. I see colleagues all around me giving everything they've got, often working 20 hour days and making many personal sacrifices to make this happen. But it's not just our leaders that have stepped up: at every level, all NHS staff have responded admirably to this crisis.

Overnight, medical and nursing students have been parachuted into the front line, starting their careers in truly extraordinary circumstances. Our junior doctor workforce has had to adapt to new working environments: many have been moved into completely unfamiliar specialties and are in the process of rapidly expanding their skill set so that they can work safely and effectively in their new teams. As junior doctors are redeployed, consultants are taking on "first on call" responsibilities for what could be an indefinite period.

My own GP colleagues have been working around the clock-redesigning clinical care pathways, reading and writing umpteen new guidelines, and doing what they can to keep people out of hospital, as well as supporting the most vulnerable people in their communities. We couldn't have done this without the help of our allied health professional workforce, especially our pharmacists, paramedics, link workers, and support staff.
Perhaps most notably, tens of thousands of retired nurses and doctors are joining us, voluntarily stepping out of retirement to help us in the fight against covid-19. It must have been all too tempting to watch this situation unfold from the comfort of their own homes, but clearly a sense of vocation is overtaking us all.

This is all happening despite much uncertainty around the adequacy of personal protective equipment and the frightening international statistics showing that a disproportionate number of healthcare professionals have died from covid-19. It's heart breaking to hear that some have even written letters to their loved ones, in case they don't make it to the other side of this.

I'm humbled to be a tiny cog in this truly outstanding NHS response. We have so much to be proud of. I hope that this chapter in our careers (however awful it may be) firmly draws a line under any accusations of lacking professionalism or any feelings of self-doubt-and that it restores our self-belief, as it's never been clearer that our healthcare workforce will rise to the challenge ahead. In my mind, there can be no greater demonstration of professionalism.

\section{Competing interests: I co-lead Islington GP Federation's Quality Improvement Team. \\ Provenance and peer review: Commissioned; not externally peer reviewed.}

Published by the BMJ Publishing Group Limited. For permission to use (where not already granted under a licence) please go to http://group.bmj.com/group/rights-licensing/ permissions 